\title{
Impact of Syzygium cumini (jamun) seed powder on dyslipidemia in type 2 diabetes mellitus: A double blind randomized control trial
}

\section{Saranshi Singh; MBBS trainee}

RUHS Medical college, Jaipur Rajasthan India
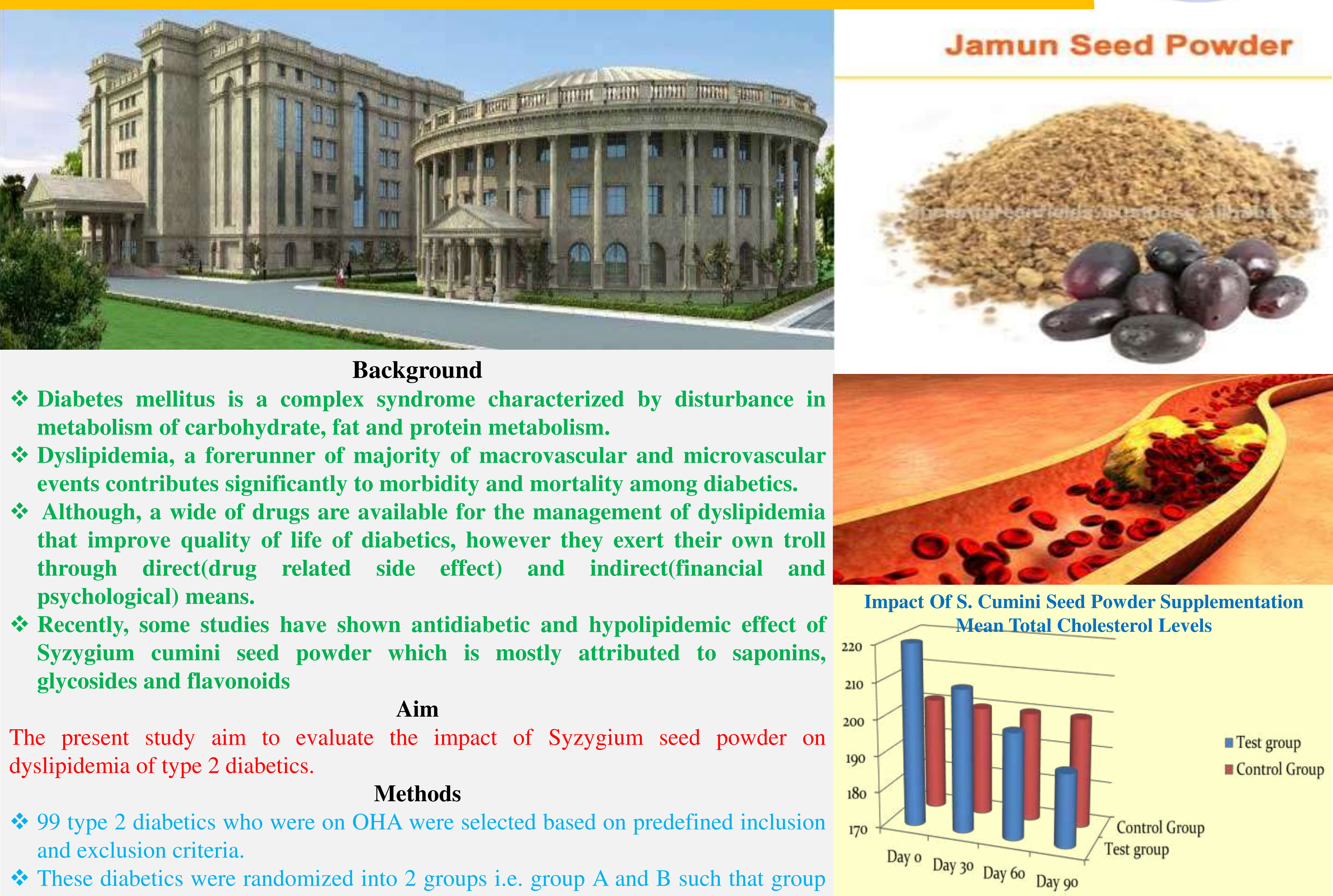

* Diabetes mellitus is a complex syndrome characterized by disturbance in metabolism of carbohydrate, fat and protein metabolism.

* Dyslipidemia, a forerunner of majority of macrovascular and microvascular events contributes significantly to morbidity and mortality among diabetics.

* Although, a wide of drugs are available for the management of dyslipidemia that improve quality of life of diabetics, however they exert their own troll through direct(drug related side effect) and indirect(financial and psychological) means.

* Recently, some studies have shown antidiabetic and hypolipidemic effect of Syzygium cumini seed powder which is mostly attributed to saponins, glycosides and flavonoids

\section{Aim}

The present study aim to evaluate the impact of Syzygium seed powder on dyslipidemia of type 2 diabetics.

\section{Methods}

99 type 2 diabetics who were on OHA were selected based on predefined inclusion and exclusion criteria.

* These diabetics were randomized into 2 groups i.e. group A and B such that group A received $10 \mathrm{gm}$. of Syzygium powder in 2 equally divided doses prior to meal whereas group B received placebo.

* Patients and investigators were blinded regarding the treatment allocated. Baseline investigations including complete lipid profile were noted and were repeated on 30th, 60th and 90th day.

* Relevant statistical test were applied and analyzed.

\section{Results}

* A statistically significant improvement in various parameters of lipid profile was usually noticed on 60th day post commencement of medication $(p<0.05)$.

* On comparison of the data from the baseline, it was noticed that mean cholesterol reduced by $10.55 \%(p<0.05)$ and $15.79 \%(p<0.001)$; TG reduced by $8.28 \%(p<0.05)$ and $13.66 \%(p<0.001)$; LDL-c reduced by $10.29(p<0.05)$ and $13.69 \%(p<0.05)$ on 60 th and 90 th day post commencement respectively.

Although, an increment of $\mathbf{5 . 4 3 \%}$ and $\mathbf{7 . 9 7 \%}$ were noted in HDL-c values post 60th and 90th day however these were not statistically significant $(p>0.05)$.

* Similarly, no statistically significant improvements were noticed in lipid profile post 30 th day of therapy $(p>0.05)$.

\section{Conclusion}

Impact Of S. Cumini Seed Powder

Supplementation Mean Triglyceride Levels

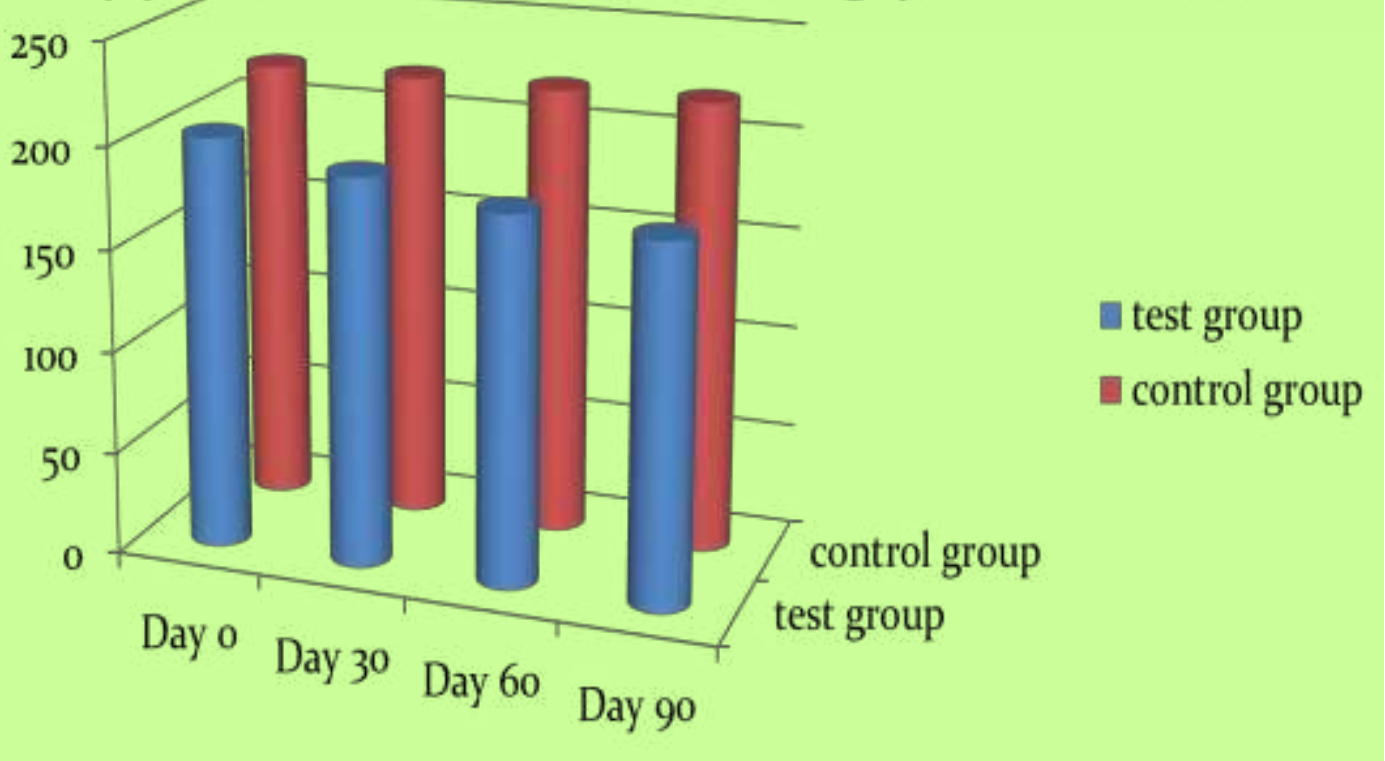

Impact Of S. Cumini Seed Powder Supplementation On Mean HDL

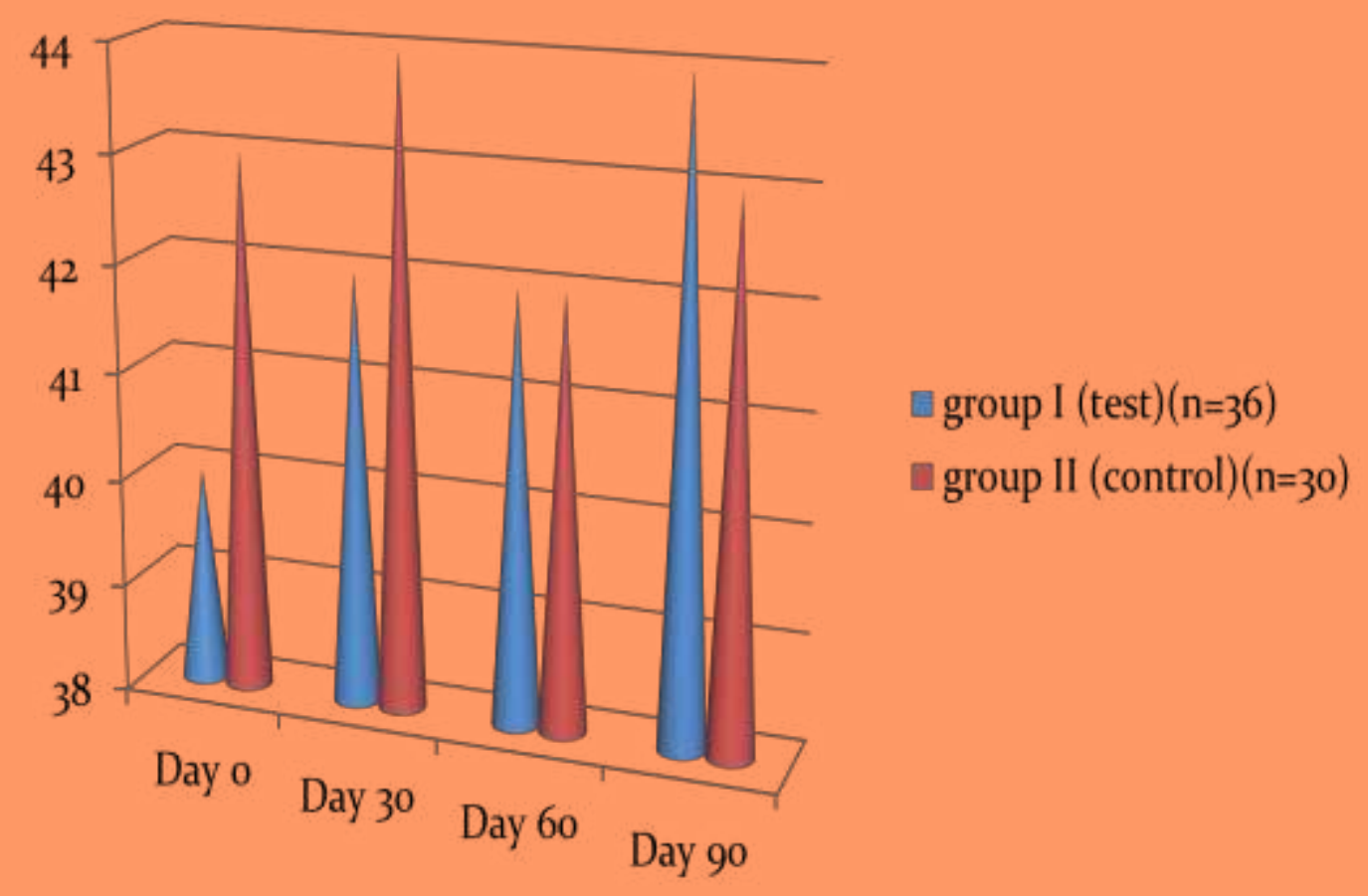

